www.jmscr.igmpublication.org

Index Copernicus Value: 79.54

ISSN (e)-2347-176x ISSN (p) 2455-0450

crossref DOI: https://dx.doi.org/10.18535/jmscr/v7i6.121

\title{
Effect of Tobacco Related Cancer Awareness Program in terms of Knowledge about Cancer among Rural Youth of Varanasi, India
}

\author{
Authors \\ Sachchidanand $^{1}$, C P Mishra ${ }^{2}$, Alok Kumar ${ }^{3}$ \\ ${ }^{1}$ Senior Resident, Department of Community Medicine Institute of Medical Sciences, Banaras Hindu \\ University, Varanasi- 221005, India \\ ${ }^{2}$ Professor, Department of Community Medicine Institute of Medical Sciences, Banaras Hindu University, \\ Varanasi- 221005, India \\ ${ }^{3}$ Associate Professor, Department of Community Medicine Institute of Medical Sciences, Banaras Hindu \\ University, Varanasi-221005, India
}

\begin{abstract}
Background: Cancer has imposed considerable human suffering and economic cost worldwide. Tobacco use contributes for major percentage of cancer-deaths worldwide.

Objective: The study was designed to evaluate the effect of Tobacco Related Cancer Awareness Program in terms of Knowledge about Cancer among Rural Youth of Varanasi.

Materials and Methods: A community based intervention study was conducted in the Varanasi district. Total one hundred eighty two youth in the age group of 15- 24 years was selected by simple random sampling. After base line assessment, subjects from two intervention villages were oriented about tobacco related cancer and effect of the same was measured by comparing finding for 2 nonintervention village. In order to draw meaningful inferences from results of the baseline and post intervention assessment, intervention and non-intervention groups were compared.

Result: Awareness of subjects from non-intervention and intervention groups was similar at the time of basal assessment. At the time of post-intervention assessment Gutkha, supari, cigarette and Bidi smoking were considered as risk factor of oral cancer by 33.0\%, 7.7\%. 23.1\% and 3.3\% subjects from nonintervention group, respectively. Corresponding values for subjects from intervention groups were $56.0 \%$. $37.4 \%, 81.3 .0 \%$ and $57.1 \%(p<0.01)$.

Conclusion: After intervention there was a significant improvement in knowledge of intervention group in terms of tobacco related cancer, manifestations of cancer, risk factor of lung cancer, most common tobacco related cancer in men and women and facility provided by Government for cancer patients.

Keywords: Cancer, Erythroplakia, Lencoplakia, Occupational hazards, Tobacco.
\end{abstract}

\section{Introduction}

Cancer is a leading cause of disease globally with an approximately 14.1 million new cancer cases occurring yearly ${ }^{1}$. It affects all people from all the age group and all the strata. According to UICC-
2006 report worldwide seventeen million new cases are expected by 2020 with three-fourth of the cancer-related deaths occurring in developing countries of the world. Among all the cancers, tobacco-related cancer (TRC) is the most common 
cancer $^{2}$. Globally tobacco is killing nearly six million every year. The number of current smokers is expected to reach 2 billion worldwide by $2030^{3}$. As the cessation of tobacco use in many countries, there is a major shift of tobacco consumption from the developed to the developing world, especially for men. Nearly $50 \%$ of men and $9 \%$ of women are current smokers in developing countries, compared with $35 \%$ of men and $22 \%$ of women in developed countries ${ }^{4}$. Tobacco addiction is a global epidemic that is ravaging the countries and regions that can least afford its toll of disability and further cause's loss of productivity and death.

One out of two young people who start smoking and continue smoking throughout their lives will lead to Tobacco related cancer ${ }^{3}$. Hence, there is an urgent need of a close monitoring of incidence of tobacco related cancer to prioritize the medical care resources and to plan the cancer control programs. India is ranked second among the consumption of tobacco globally, and accounts for approximately one-sixth of the world's tobaccorelated deaths. Nearly $30 \%$ of cancers in India are related to tobacco use ${ }^{5}$. Various studies have shown strong association of tobacco use in India and cancer at various sites. Almost half of all cancers in men occur at sites (mouth, lip and tongue, oropharynx, hypo pharynx, pharynx, oesophagus, larynx, lung and urinary bladder) associated with tobacco use. In women, less than one fifth of cancers occur at these sites, mainly in oesophagus and oral cavity. The number of newly diagnosed tobacco related cancer each year in India has been estimated at approximately $250,000{ }^{6}$. Murthy et al., (2009) studied the risk of developing cancer in India in the age group of 35$70+$ years. The finding of the study showed that the probability of developing tobacco related cancers was high in males $(4.75 \%)$ as compared to females $(2.16 \%)$. He further concluded that out of the total cancer cases nearly $45 \%$ in males and $20 \%$ in females are due to tobacco use ${ }^{7}$.

Cancer related to tobacco use is preventable through primary prevention.Information about the awareness regarding tobacco related cancers in Rural Youth of India is low. The need of era demands for a tailored approach to promote health education and to increase awareness about tobacco related cancer. There is an urgent demand for understanding the process of initiation of tobacco product, extent and reasons of consumption, consequences of tobacco use in terms of causation of cancer, early signs of cancer etc. In this study attempt has been made to design and execute an education package in terms of knowledge about tobacco related cancer among rural youth and to demonstrate its effect in terms of knowledge of the rural youth of Varanasi district, India regarding tobacco related cancer.

\section{Material \& Method}

The study was conducted in Kashi vidya peeth community Development (CD) Block of Varanasi district, India.

Study design: This is a community based intervention study adopted quasi experimental design

Sample Size: Sample size for each arm was estimated by using the formula-

$$
N=K \times \frac{p_{1}\left(1-p_{1}\right)+p_{2}\left(1-p_{2}\right)}{(P 1-p 2)^{2}}
$$

Where $\mathrm{K}=$ Constant which is a function of $\alpha$ and $\beta$

$$
\left(\mathrm{Z}_{\alpha / 2}+\mathrm{Z}_{\beta}\right)^{2}
$$

Taking $\alpha=0.05$ and power of the $80 \%$

$$
\begin{aligned}
\mathrm{K} & =\left(\mathrm{Z}_{0.05 / 2}+\mathrm{Z}_{0.20}\right)^{2} \\
& =(1.96+0.842)^{2} \\
& =(2.802)^{2} \\
& =7.9
\end{aligned}
$$

Assuming $\mathrm{P}_{1}=$ Proportion of subjects knowledge before intervention $=0.3$

$\mathrm{P}_{2}=$ Proportion of subjects knowledge after intervention $=0.5$

$$
\begin{aligned}
\mathrm{N} & =7.9 \times \frac{[0.3 \times 0.7+0.5 \times 0.50]}{(0.3-0.5)^{2}} \\
& =91
\end{aligned}
$$

Thus the estimated sample size worked out to be 91 for each arm. 
Sampling Methodology: Following steps were involved in the selection of study subjects. One community development block (Kashi Vidya peeth block) was selected from 8 Community Developments Block of Varanasi District by simple random sampling.In the selected Community Developments Block 4 villages (Bacchaw, Hariharpur, Badagaon Pratham, and Tikari) were selected by stratified random sampling; stratification was done on the basis of distance from the block headquarters. Proportionate numbers of study subjects were selected by simple random sampling methods from the universe of youths aged 15-24 years. At the time of post assessment three replacement samples were taken from non-intervention villages.

Inclusion Criteria: Only permanent residents consenting for the study were included in the study.

Exclusion Criteria: Subjects with obvious mental retardation and lack of understanding were excluded from the study.

Tools and technique: Family level information was obtained by interviewing study subjects/ head of the family or any other responsible family member on the predesigned and pretested proforma. Besides providing family level information this schedule was specifically designed to examine knowledge of study subjects regarding tobacco related cancer. This study was carried out in 3 phases- Pre-interventional phase, interventional phase and Post-interventional phase. In the first phase knowledge of the study subjects regarding tobacco related cancer were accessed by interviewing them with the proforma. Based on the findings of the study, educational package was evolved and educational materials were developed in Hindi in the form of posters and charts. Thus developed study material was pretested on sample of rural youth from a nonstudy village for comprehensibility, content and construct. In the intervention phaseout of 4 selected villages, 2 were selected as intervention group by lottery method and other 2 villages were considered as non-intervention group. Out of 182 subjects selected during intervention phase, 91 were in intervention villages. They were oriented in a group of 20-25 about different types of tobacco and adverse effects of their consumption, initiation of causation of cancer, symptoms, causes, risk factors, prevention and screening of cancer. Finally in the post-interventional stage information pertaining to key parameters regarding knowledge of tobacco related cancer was obtained by interviewing subjects from intervention and non-intervention villages.

Ethical Approval: Before starting the study ethical approval was obtained by Institutional Ethical Committee of Banaras Hindu University and Consent was obtained by using bilingual consent form.

Analysis of data: Data thus generated were analyzed by using Statistical Packages for Social Sciences (SPSS) version 20. Appropriate tables were generated and $t$ test was applied for statistical association and inference.

\section{Result}

Awareness of subjects from non-intervention and intervention groups were similar at the time of basal assessment (except for Khaini as risk factor of oral cancer) in terms of tobacco consumption and its consequences, awareness about manifestations of cancer, risk factor of oral and lung cancer, most common tobacco related cancer in women and men and facility provided by government for cancer patients. At the time of baseline assessment awareness about Khaini as risk factor of oral cancer was significantly $(\mathrm{p}<0.01)$ more in subjects for non-intervention group $72.5 \%$ than these in the intervention group $57.1 \%$ (Table 1 ). 
Table- 1: Awareness of study subjects regarding tobacco related cancers at baseline (Non-intervention vs. Intervention group).

\begin{tabular}{|c|c|c|c|c|c|c|}
\hline \multirow[t]{2}{*}{ Parameter } & \multicolumn{2}{|c|}{$\begin{array}{l}\text { Non-intervention } \\
\text { group }(\mathrm{N}=91\end{array}$} & \multicolumn{2}{|c|}{$\begin{array}{l}\text { Intervention Group } \\
(\mathrm{N}=91)\end{array}$} & \multicolumn{2}{|c|}{ Test of significance } \\
\hline & No. & $\%$ & No. & $\%$ & z score & p value \\
\hline $\begin{array}{l}\text { Tobacco consumption in any form } \\
\text { causes cancer? }\end{array}$ & 83 & 91.2 & 81 & 89.0 & 0.49 & $>0.05$ \\
\hline \multicolumn{7}{|c|}{ Tobacco consumption in any form cause cancer at following site: } \\
\hline - Lung & 33 & 36.3 & 31 & 34.1 & 0.03 & $>0.05$ \\
\hline - Oral & 34 & 37.4 & 33 & 36.3 & 0.15 & $>0.05$ \\
\hline - Esophagus & 1 & 1.1 & 1 & 1.1 & 0 & $>0.05$ \\
\hline - Kidney & 1 & 1.1 & 0 & 0.0 & 0 & $>0.05$ \\
\hline \multicolumn{7}{|c|}{ Awareness about Manifestations of cancer: } \\
\hline - Unexplained Lump & 13 & 14.3 & 14 & 15.4 & 0.20 & $>0.05$ \\
\hline - Unexplained Pain & 30 & 33.0 & 24 & 26.4 & 0.97 & $>0.05$ \\
\hline - Unexplained bleeding & 31 & 34.1 & 28 & 30.8 & 0.47 & $>0.05$ \\
\hline - $\quad$ Persistent cough & 27 & 29.7 & 21 & 23.1 & 1.00 & $>0.05$ \\
\hline - Persistent change in bowel & 23 & 25.1 & 24 & 26.4 & 0.16 & $>0.05$ \\
\hline - $\quad$ Restricted mouth opening & 1 & 1.1 & 2 & 2.2 & 0.58 & $>0.05$ \\
\hline - $\quad$ Fever & 3 & 3.3 & 2 & 2.2 & 0.45 & $>0.05$ \\
\hline - $\quad$ Non-healing ulcer & 1 & 1.1 & 1 & 1.1 & 0 & $>0.05$ \\
\hline - Lencoplacia & 2 & 2.2 & 1 & 1.1 & 0.58 & $>0.05$ \\
\hline - $\quad$ Erythoplacia & 1 & 1.1 & 2 & 2.2 & 0.58 & $>0.05$ \\
\hline \multicolumn{7}{|l|}{ Risk factor of oral cancer : } \\
\hline - Khaini & 66 & 72.5 & 52 & 57.1 & 2.17 & $<0.01$ \\
\hline - Gutkha & 30 & 33.0 & 23 & 25.3 & 1.14 & $>0.05$ \\
\hline - Supari & 7 & 7.7 & 4 & 4.4 & 0.93 & $>0.05$ \\
\hline - $\quad$ Cigarette Smoking & 21 & 23.1 & 15 & 16.5 & 1.11 & $>0.05$ \\
\hline - $\quad$ Bidi Smoking & 3 & 3.3 & 2 & 2.2 & 0.45 & $>0.05$ \\
\hline \multicolumn{7}{|l|}{ Rick factors of Lung cancer } \\
\hline - $\quad$ Active smoking & 66 & 72.5 & 58 & 63.7 & 1.27 & $>0.05$ \\
\hline - $\quad$ Passive smoking & 1 & 1.1 & 1 & 1.1 & 0 & $>0.05$ \\
\hline - Occupational hazards & 1 & 1.1 & 1 & 1.1 & 0 & $>0.05$ \\
\hline \multicolumn{7}{|c|}{ Most common tobacco related cancer in women } \\
\hline - $\quad$ Oral cavity & 24 & 26.4 & 22 & 24.2 & 0.34 & $>0.05$ \\
\hline - Lung cancer & 9 & 9.9 & 10 & 11.0 & 0.02 & $>0.05$ \\
\hline \multicolumn{7}{|c|}{ Most common tobacco related cancer in man } \\
\hline - $\quad$ Oral cavity & 11 & 12.1 & 12 & 13.2 & 0.22 & $>0.05$ \\
\hline - Lung cancer & 11 & 12.1 & 14 & 15.4 & 0.64 & $>0.05$ \\
\hline \multicolumn{7}{|c|}{ Facility provided by the Government for cancer patient } \\
\hline - Economic & 3 & 3.3 & 4 & 4.4 & 3.8 & $>0.05$ \\
\hline - $\quad$ Transport & 3 & 3.3 & 2 & 2.2 & 0.45 & $>0.05$ \\
\hline - $\quad$ Treatment & 5 & 5.5 & 3 & 3.3 & 0.72 & $>0.05$ \\
\hline
\end{tabular}

In comparison to non-intervention group educational package was effective in enhancing knowledge of intervention group significantly $(p<0.01)$ in terms of tobacco related cancer, manifestations of cancer, risk factor of lung cancer, most common tobacco related cancer in men and women and facility provided by Governments for cancer patients. At the time of post-intervention assessment Gutkha, supari, cigarette as well as Bidi smoking were considered as risk factor of oral cancer by $33.0 \%, 7.7 \%$. $23.1 \%$ and $3.3 \%$ subjects from non-intervention group, respectively. Corresponding values for subjects from intervention groups were $56.0 \%$. $37.4 \%, 81.3 .0 \%$ and $57.1 \%(\mathrm{p}<0.01)$. During this phase Khaini as a risk factor of oral cancer was considered by $72.5 \%$ and $82.4 \%$ subjects belonging to non-intervention and intervention groups, respectively (Table 2). 
Table- 2: Awareness of study subjects (Non-intervention Vs. intervention group) regarding tobacco related cancers during Post intervention assessment

\begin{tabular}{|c|c|c|c|c|c|c|}
\hline \multirow[t]{2}{*}{ Parameter } & \multicolumn{2}{|c|}{$\begin{array}{l}\text { Non-intervention } \\
\text { group }(\mathrm{N}=91\end{array}$} & \multicolumn{2}{|c|}{$\begin{array}{c}\text { Intervention Group } \\
(\mathrm{N}=91)\end{array}$} & \multicolumn{2}{|c|}{ Test of significance } \\
\hline & No. & $\%$ & No. & $\%$ & z score & p value \\
\hline \multicolumn{7}{|c|}{ Tobacco consumption in any form cause cancer at following site } \\
\hline - $\quad$ Lung & 33 & 36.3 & 81 & 89.0 & 7.35 & $<0.01$ \\
\hline - $\quad$ Oral & 34 & 37.4 & 85 & 93.4 & 7.94 & $<0.01$ \\
\hline - $\quad$ Esophagus & 1 & 1.1 & 66 & 72.5 & 9.98 & $<0.01$ \\
\hline - $\quad$ Kidney & 1 & 1.1 & 42 & 46.2 & 7.15 & $<0.01$ \\
\hline \multicolumn{7}{|c|}{ Awareness about Manifestations of cancer } \\
\hline - $\quad$ Unexplained Lump & 13 & 14.3 & 80 & 87.9 & 9.93 & $<0.01$ \\
\hline - Unexplained Pain & 30 & 33.0 & 62 & 68.1 & 4.47 & $<0.01$ \\
\hline - Unexplained bleeding & 31 & 34.1 & 78 & 85.7 & 7.10 & $<0.01$ \\
\hline - $\quad$ Persistent cough & 27 & 29.7 & 60 & 65.9 & 4.89 & $<0.01$ \\
\hline - $\quad$ Persistent change in bowel & 23 & 25.1 & 51 & 56.0 & 4.22 & $<0.01$ \\
\hline - $\quad$ Restricted mouth opening & 1 & 1.1 & 75 & 82.4 & 11.12 & $<0.01$ \\
\hline - $\quad$ Fever & 3 & 3.3 & 44 & 48.4 & 6.94 & $<0.01$ \\
\hline - $\quad$ Non-healing ulcer & 1 & 1.1 & 38 & 41.8 & 6.68 & $<0.01$ \\
\hline - Lencoplacia & 2 & 2.2 & 31 & 34.1 & 5.57 & $<0.01$ \\
\hline - $\quad$ Erythoplacea & 1 & 1.1 & 58 & 63.7 & 9.02 & $<0.01$ \\
\hline \multicolumn{7}{|l|}{ Risk factor of oral cancer : } \\
\hline - Khaini & 66 & 72.5 & 75 & 82.4 & 1.59 & $>0.05$ \\
\hline - Gutkha & 30 & 33.0 & 51 & 56.0 & 3.13 & $<0.01$ \\
\hline - $\quad$ Supari & 7 & 7.7 & 34 & 37.4 & 4.79 & $<0.01$ \\
\hline - $\quad$ Cigarette Smoking & 21 & 23.1 & 74 & 81.3 & 7.86 & $<0.01$ \\
\hline - $\quad$ Bidi Smoking & 3 & 3.3 & 52 & 57.1 & 7.90 & $<0.01$ \\
\hline \multicolumn{7}{|l|}{ Rick factors of Lung cancer } \\
\hline - $\quad$ Active smoking & 66 & 72.5 & 83 & 91.2 & 3.27 & $<0.01$ \\
\hline - $\quad$ Passive smoking & 1 & 1.1 & 75 & 82.4 & 11.12 & $<0.01$ \\
\hline - $\quad$ Occupational hazards & 1 & 1.1 & 66 & 72.5 & 9.98 & $<0.01$ \\
\hline \multicolumn{7}{|c|}{ Most common tobacco related cancer in women } \\
\hline - $\quad$ Oral cavity & 24 & 26.4 & 66 & 72.5 & 6.22 & $<0.01$ \\
\hline - Lung cancer & 9 & 9.9 & 25 & 27.5 & 3.04 & $<0.01$ \\
\hline \multicolumn{7}{|c|}{ Most common tobacco related cancer in man } \\
\hline - Oral cavity & 11 & 12.1 & 35 & 38.5 & 4.09 & $<0.01$ \\
\hline - Lung cancer & 11 & 12.1 & 56 & 61.5 & 6.91 & $<0.01$ \\
\hline \multicolumn{7}{|c|}{ Facility provided by the Government for cancer patient } \\
\hline - Economic & 3 & 3.3 & 56 & 61.5 & 8.99 & $<0.01$ \\
\hline - $\quad$ Transport & 3 & 3.3 & 61 & 67.0 & 9.57 & $<0.01$ \\
\hline - $\quad$ Treatment & 5 & 5.5 & 91 & 100.0 & 13.49 & $<0.01$ \\
\hline
\end{tabular}

\section{Discussion}

Tobacco related cancers (TRC) are the most common cancers and it account for major share of all cancers. A study done by Asthana et al., (2016) revealed that up to one-fourth of all cancers among men and little lower than one-fifth among women was tobacco related ${ }^{8}$. Among all important Tobacco related Cancer sites, the risk of getting lung cancer was higher in most regions of the country and esophageal cancer was highest for both men and women of North eastern region.
D'Souza et al., (2013) in his study stated that Lung cancer was important site for women and this was a most commonly occurring cancer and its risk was equal to the risk of getting esophageal cancer. Lung and hypopharynx cancers were the second most common site among men with risk of 1 out of every $67^{9}$. In Present study, keeping in mind that subjects belonging to intervention and non-intervention area be similar in basal characteristics, important tobacco related cancer sites were compared. At the base line awareness 
of subjects from non-intervention and intervention groups were similar. Below half of the population was unaware of the important tobacco related cancer sites. Post intervention there was significant improvement in the knowledge of interventional group. More than half of the population was aware of the fact that Lung, Oral and Esophagus were the most important tobacco related cancer sites.

In the present study awareness about various manifestations of cancer was poor. Less than $20 \%$ of the subjects were unaware that unexplained lump, unexplained pain, unexplained bleeding, persistent cough or hoarseness and persistent change in bowel and bladder habit are manifestations of cancer. At baseline no significant $(p<0.05)$ difference existed in the awareness of interventional and noninterventional group. Education is one of the major factors that help to create awareness. Younger age groups had more informationseeking behavior, and the education level was linked to increased requests for additional information ${ }^{10}$. Literacy is directly related to awareness level. More knowledge among those who were literate than among those who did not have any formal education ${ }^{11}$. Gopal \& Duraiselvi, (2014) in their study found that the general awareness, knowledge of signs and risk factor of oral cancer had been least among illiterates' youth $^{12}$. In the present study intervention package was found to be effective in enhancing knowledge of subjects from intervention group in terms of tobacco related cancer, manifestations of cancer, risk factor of lung cancer, most common tobacco related cancer in men and women and facility provided by Government for cancer patients. Post intervention there was significant improvement in awareness about various manifestations of cancer. More than $80 \%$ of the population agreed that Unexplained Lump, Unexplained bleeding and restricted mouth opening were important manifestations of cancer. Significant improvement was observed about other manifestations of cancer. Finding of the current study emphasizes on the need of an integrated educational approach and agro-economic strategy besides legislative framework. Anti-tobacco education needs to be targeted especially the youth. Extensive outreach of tobacco products in the remote corner of village even at small shops calls for prioritizing our action on rural youth.

Overall knowledge of various risk factors of cancer in the current study was not up to the mark. However more than half of the population considered khaini and active smoking as a risk factor of tobacco related cancer. This finding can be due to the constant effort of Government. Government of India has initiated several measures for enforcing legislations to prevent young people from having any access to tobacco. Tobacco smoking in public places in the form of cigarette, bidis and cigars are prohibited. The changes observed between subjects from intervention and non-intervention groups at the time of post intervention phase and pre and post assessments of subjects belonging to intervention group have been significant for all parameters except khaini as risk factors for oral cancer.

In India nearly half of the tobacco users consume tobacco in smokeless form. The threat of tobacco consumption necessitates multi-sectoral approach where in different sectors can provide synergistic role to bring out major social change leading to tobacco control. The efficacy of anti-tobacco community education programme involving schools and community education has been demonstrated by Indian Council of Medical Sciences. In the present context media outreach has taken a significant change and there is a need to shift from radio to multimedia approach.

Facilities provided by the Government were practically unknown to the rural youth. At baseline less than $10 \%$ of the population was unaware of the facilities provided by the Government. In conformity with the findings of this study, poor knowledge about cancer awareness camps has been observed in a study conducted in six states of India ${ }^{13}$. Post intervention there was significant improvement in 
the knowledge about government facilities in the interventional group, thus establishing the need of Tobacco Related Cancer Awareness Programme in terms of Knowledge about Cancer among Rural Youth of Varanasi.

\section{Conclusion}

The findings of the study support the fact that the Evidence-based interventions are urgently needed to address the rising public health epidemic of tobacco use in the developing world. Little research has examined the efficacy of tobacco related cancer awareness programme for rural youth in India. In future the circulation of cancer information through the mass and other forms of media should be intensified to increase the level of cancer awareness and the importance of cancer screening among the general population.

\section{Conflict of Interest: None}

\section{References}

1. Global Cancer Facts \& Figures. Available from:

https://www.cancer.org/research/cancer-

facts-statistics/global.html. Last accessed on 4/4/2019.

2. Cancer Awareness, Prevention and Control: Strategies for South Asia. (UICC2006). Available

from: https://www.uicc.org/resources/cancer -awareness-prevention-and-control-uicc-

handbook-south-asiaLast accessed on 8/6/2019].

3. Mackay J, Eriksen M, Shafey O. The Tobacco Atlas. 2nd. Geneva, Switzerland: World Health Organization; 2006. [June 2010]. Available: http://www.cancer.org /docroot/AA/content

/AA_2_5_9x_Tobacco_Atlas.asp.

4. Shafey O, Eriksen M, Ross H, Mackay J. The tobacco atlas. Atlanta: American Cancer Society; 2009.
5. Reddy KS, Gupta PC. Tobacco control in India. New Delhi: Ministry of Health and Family Welfare, Government of India. 2004:43-7.

6. Gupta PC, Ray CS. Tobacco related cancerits impact on the health economy. Health Administrator. 2005;17:85-92.

7. Murthy NS, Rajaram D, Gautham MS, Shivaraj NS, Nandakumar BS, Pruthvish S. Risk of cancer development in India. Asian Pac J Cancer Prev. 2011 Jan 1; 12:387-91.

8. Asthana S, Patil RS, Labani S. Tobaccorelated cancers in India: A review of incidence reported from population-based cancer registries. Indian journal of medical and pediatric oncology: official journal of Indian Society of Medical \&Pediatrics Oncology. 2016 Jul; 37(3):152.

9. D'Souza ND, Murthy NS, Aras RY. Projection of cancer incident cases for India-till 2026. Asian Pacific Journal of cancer prevention. 2013; 14(7):4379-86.

10. Brokalaki EI, Sotiropoulos GC, Tsaras K, Brokalaki H. Awareness of diagnosis, and information-seeking behavior of hospitalized cancer patients in Greece. Supportive care in cancer. 2005 Nov 1; 13(11):938-42.

11. Elangovan V, Rajaraman S, Basumalik B, Pandian D. Awareness and Perception about Cancer among the Public in Chennai, India. Journal of global oncology. 2016 Nov 9; 3(5):469-79.

12. Gopal SK and Duraiselvi P. Awareness and Knowledge of Oral Cancer among Dental Patients: A Survey Based Questionnaire Study. IJAHS 2014, 1(7): 12-15.

13. Raj S, Piang LK, Nair KS, Tiwari VK, Kaur $\mathrm{H}$, Singh B. Awareness regarding risk factors, symptoms and treatment facilities for cancer in selected states of India. Asian Pacific Journal of Cancer Prevention. 2012;13(8):4057-62. 